\title{
REPRESENTAÇÕES DE DOCENTES SOBRE VIOLÊNCIA NAS ESCOLAS: UM ESTUDO EM UMA ESCOLA RIBEIRINHA
}

\author{
Vivian da Silva LOBATO ${ }^{1}$ \\ Universidade Federal do Pará/UFPA \\ vivianlobato@ufpa.br
}

Resumo: Este trabalho de pesquisa orientou-se pelo objetivo de analisar as representações de professores sobre violência no contexto escolar. A coleta de dados foi realizada em uma Escola ribeirinha e quilombola. Foi realizada pesquisa bibliográfica, seguida de entrevistas com seis (6) professores de uma Escola de Estadual de Ensino Fundamental e Médio do Município de Abaetetuba, no Estado do Pará. Os professores entrevistados trabalham no Ensino Médio da Escola Santos André. Com o objetivo de preservar o anonimato, atribuíram-se nomes fictícios na apresentação e discussão dos resultados. Optou-se por agrupar os dados em categorias de significados, ao final foram elencadas nove (9) categorias, quais sejam: $O$ que os professores conversam sobre a violência, formas de violência manifestas na escola, a violência considerada a mais grave, como a violência é trabalhada em sala de aula, como os professores costumam agir diante da violência, a formação sobre violência escolar, a violência na relação professor-aluno, a infraestrutura da escola X violência, consequências da violência para a escola. O referencial teórico-metodológico utilizado assentou-se nos estudos dos seguintes pesquisadores: Franco (2004), Charlot (2002), Fante (2005), Placco (2005), Kodato (2010) e Pedro-Silva (2014). Foi possivel constatar a falta de formação docente para lidar com a violência, o vácuo estratégico e o medo dos professores que, embora percebam a complexidade do problema ainda procuram na família a principal origem da violência.

Palavras-chave: Violência. Escola quilombola. Professores.

\footnotetext{
${ }^{1}$ Professora Adjunta da Faculdade de Educação e Ciências Sociais da UFPA - Campus de Abaetetuba. Doutora em Educação: Psicologia da Educação. E-mail: vivianlobato@yahoo.com.br
} 
Abstract: This research was guided by the objective of analyzing the conceptions of teachers about violence in school context. Data collection was performed in a riverine and quilombo School. A literature review was performed, followed by interviews with six (6) teachers in a State of Elementary School and Middle of the Municipality of Abaetetuba, State of Para. The interviewed teachers working in High School School André Santos. In order to preserve anonymity, attributed to fictitious names in the presentation and discussion of results. it was decided to group the data into categories of meaning, the end were listed nine (9) categories, namely: What teachers talk about violence, forms of violence manifest in school, violence considered the most serious, such as violence is crafted in the classroom, as teachers often act in the face of violence, training on school violence, violence in the teacher-student relationship, the infrastructure of the school $\mathrm{X}$ violence, consequences of violence for school. The theoretical framework used sat in the studies of the following researchers: Franco (2004), Charlot (2002), Fante (2005), Placco (2005), Kodato (2010) and Peter-Silva (2014). It was found the lack of teacher training to deal with violence, the strategic vacuum form working with this problem.

Keywords: Violence. Quilombo School. Teachers. 


\section{INTRODUÇÃO}

As diferentes manifestações de violência nas escolas vêm adquirindo cada vez mais visibilidade e dramaticidade na sociedade brasileira. Muitas são as suas expressões, os sujeitos envolvidos e as consequências. Tal problemática possui muitas implicações do ponto de vista da prática educativa e suas manifestações no espaço escolar têm preocupado pais e educadores. Dentro de tal contexto, esta pesquisa pretende levantar questões que possam contribuir para uma reflexão sobre o fenômeno da violência e suas implicações na prática pedagógica das escolas. Tem por finalidade provocar uma discussão sobre o que pensam os/as professores/as sobre a problemática das relações entre violência e escola. Sendo assim, o objetivo desse artigo é analisar as representações de professores sobre violência no contexto escolar.

$\mathrm{O}$ presente estudo originou-se de pesquisa realizada pelo projeto de pesquisa "Representações de professores das Ilhas de Abaetetuba sobre violência nas escolas". Projeto este ligado à Faculdade de Educação e Ciências Sociais da Universidade Federal do Pará, Campus Universitário de Abaetetuba. Além da pesquisa bibliográfica, foram realizadas entrevista com seis professores de uma Escola Estadual de Ensino Fundamental e Médio do Município de Abaetetuba, no Estado do Pará. Os professores entrevistados trabalham no Ensino Médio da Escola Santos André. Com o objetivo de preservar o anonimato, atribuíram-se nomes fictícios aos docentes na apresentação e na discussão dos resultados.

Para a coleta de dados, utilizou-se as entrevistas semiestruturadas, buscando compreender o entendimento e as atitudes de tais professores perante a incidência de violência na referida escola. A utilização dessa metodologia teve como objetivo principal refletir sobre o que esses docentes pensavam sobre a violência na escola hoje; e também verificar algumas experiências relacionadas a estes fenômenos no cotidiano escolar. Após as transcrições das entrevistas, optamos por agrupar os dados em categorias de significados. Categorização, segundo Maria Laura Franco (2003), é definida como "uma operação de classificação de elementos constitutivos de um conjunto, por diferenciação seguida de um reagrupamento baseado em analogias, a partir de critérios definidos" (p.59). Foram selecionados aspectos dos fenômenos retirados das falas dos participantes da pesquisa, bem como das respostas ao questionário, e foram agrupados a partir das suas unidades de sentidos. Dessa maneira, as categorias foram estabelecidas de acordo com 
aspectos das falas que apareceram mais significativamente, seguindo o objetivo da pesquisa.

\section{O LÓCUS DA PESQUISA}

Baixo Itacuruçá é uma comunidade ribeirinha localizada em Abaetetuba, Pará, próximo às cidades de Moju e de Igarapé-Miri. Está dentro do território quilombola Ilhas de Abaetetuba, juntamente com mais sete comunidades: Alto Itacuruçá, Campopema, Jenipaúba, Acaraqui, Igarapé São João, Arapapu e Rio Tauaré-Açu. (WIKINATIVA, 2015)

Segundo o Instituto de Terras do Pará (WIKINATIVA, 2015), o território Ilhas de Abaetetuba tem população de 701 famílias e área de 11.458.5300 ha. O Baixo Itacuruçá, por sua vez, tem 116 famílias e uma população de 580 pessoas. Trata-se de uma comunidade rural, quilombola e ribeirinha, cuja principal fonte de renda é a venda de açaí, manga, pescados e plantas medicinais, nas cidades mais próximas.

A pesquisa de campo foi realizada na comunidade rural conhecida como Baixo Itacuruçá, na Escola Quilombola Santo André. Os professores, que se encontram lotados na Escola Benvinda de Araújo Pontes, de Abaetetuba, deslocam-se até o Itacuruçá para dar aula uma vez por semana.

Foram entrevistados seis professores, sendo duas mulheres e quatro homens. Nenhum deles se declarou natural das Ilhas do Abaetetuba. Todos são efetivos da Escola Professora Benvinda de Araújo Pontes. São eles:

- Professor 1 - Licenciado em Geografia. Trabalha com educação há seis anos, sendo dois na Escola Quilombola Santo André.

- Professor 2 - Graduado em História, Especialista em Comunicação e Marketing e Mestrando em Educação. Trabalha com Educação há dezesseis anos.

- Professor 3 - Licenciado em Química. Trabalha há 7 meses, atuando na Escola Quilombola Santo André.

- Professor 4 - Especialista em Língua Portuguesa e Literatura. Trabalha há treze anos, há três anos na Escola Quilombola Santo André. 
- Professor 5 - Graduado em Sociologia. Trabalha como professor há 17 anos, há três, na Escola Quilombola Santo André.

- Professor 6 - Graduado em Educação Física. Trabalha há cinco anos na Escola Quilombola Santo André.

\section{CONCEITUANDO VIOLÊNCIA}

Primeiramente, se faz necessário conceituar o que se entende por violência e depois o que se entende por violência nas escolas. De acordo com o dicionário Houaiss (2009), a etimologia do termo violência, violentia, é latina e refere-se à impetuosidade do vento, rigor, severidade.

1. uso de força física; 2. ação de intimidar alguém; 3. ação destrutiva, exercida com ímpeto, força; 4. expressão ou sentimento vigoroso, fervor (Houaiss, 2009, p.762).

Segundo Chauí (1998), a violência pode ser entendida como ações com o uso de forçar contra a natureza de um ser; ato contra a vontade e liberdade de alguém (coerção ou constrangimento); ato de violação de uma pessoa ou objetos socialmente valorizados; ato de transgredir ações definidas como justas e de direito, por uma sociedade.

De acordo com Zaluar (1999), a própria etimologia do termo vis (força), bem como a sua variação histórica e cultural, dificulta a sua definição.

\section{VIOLÊNCIA NAS ESCOLAS: UM FENÔMENO DAS RELAÇÕES SOCIAIS}

Com relação à conceituação da violência nas escolas, os autores consultados neste trabalho destacam que ela deve ser considerada com base no contexto cultural e histórico em que ela está inserida.

Abramovay e Rua (2002) entendem que a violência nas escolas é constituída por manifestações que podem variar quanto aos objetivos, alvos, instrumentos, vítimas e protagonistas. Segundo as autoras as manifestações de violência podem ser categorizadas por:

(1) Violência contra a pessoa, expressa verbal ou fisicamente: as ameaças, as brigas, a violência sexual, a coerção, mediante o uso de armas; 
(2) Violência contra a propriedade: furtos, roubos e assaltos;

(3) Violência contra o patrimônio, especificamente o vandalismo e depredação das instalações escolares (p. 232).

De acordo com Abramovay e Rua (2002), a violência merece ser estudada como uma ruptura de pactos sociais por meio da força física ou simbólica, ocorrendo em uma variedade de situações, capazes de danificar os laços sociais. As autoras também apontam situações, que, no limite, podem engendrar ocorrências violentas na escola, tais como: indisciplina, não explicação das normas de organização da escola, carência de recursos humanos e materiais, baixos salários dos professores, falta de infraestrutura (laboratórios, biblioteca, quadras esportivas e etc.), gestão escolar autoritária, não integração da família e da comunidade ao ambiente escolar.

Charlot (2002) sublinha que é preciso fazer uma diferenciação entre violência na escola, violência à escola e a violência da escola.

A violência na escola é aquela que se produz dentro do espaço escolar, sem estar ligado à natureza e às atividades da instituição escolar. Por exemplo, quando um bando entra na escola para acertar contas e disputas, a escola é apenas o lugar de uma violência que poderia ter acontecido em qualquer outro local.

A violência à escola visa à instituição e aqueles que a representam. Ela acontece quando os alunos depredam a escola, insultam professores e funcionários. Junto com essa violência contra a instituição escolar, deve ser analisada a violência da escola, ou seja, uma violência institucional, simbólica, das relações de poder entre professores e alunos, além de atos considerados pelos alunos como injustos ou racistas.

Assim sendo, para fins de conceituação, a violência é considerada nessa pesquisa como todo dano (físico psicológico ou moral) que se impõe a pessoas ou grupos.

\section{Resultados e Discussão}

\section{$1 O$ que os professores conversam sobre a violência}

Ao comentar sobre o que os docentes conversam a respeito da violência, o professor Lauro verbaliza que violência está presente na realidade ribeirinha, seja ela física, sexual ou social, porém ela acontece de forma camuflada, a ponto de as pessoas da localidade terem até medo de denunciar alguns fatos. 
Violência contra menores é constante aqui. As pessoas têm medo de denunciar. Você vê uma garota de treze anos, quatorze anos, e... já se torna quase que comum a forma como ela engravidou, e as pessoas já não discutem muito e acabam não denunciando esse tipo de violência. (Lauro)

O professor Mauro evidencia a violência familiar e doméstica presentes naquela localidade.

Na verdade, tivemos muitos casos de violência familiar; é algo comum. Ontem mesmo, quando nós conversávamos com nossos alunos, um nos contou que seu tio tinha incendiado a casa da sua irmã”. (Mauro)

Para o professor Mauro, a impunidade que existe na comunidade é um dos principais motivos dessas violências na localidade.

A professora Maíra reflete bem esse "espanto" que surpreende aqueles que tinham uma representação da escola como um ambiente pacato, puro, seguro, em contraposição à representação que se tem da vida nas cidades, permeadas pelas violências e criminalidade.

Aí, pensamos: 'Poxa! Não acredito! Imaginamos que a violência fica somente na cidade. (Maíra)

De fato, a violência está sim enraizada na comunidade pesquisada. Uma violência que se tenta camuflar, mas que não é silenciosa, porque se manifesta e é não só perceptível como também relatada pelos entrevistados.

\section{Formas de violência manifestas na escola}

Para o professor, a violência que mais chama a atenção na escola é a violência contra os direitos sociais, especificamente a falta de garantia dos direitos sociais da comunidade quilombola.

Eu diria que, dentro do espaço escolar, a violência mais presente é a violência no sentido da garantia de direitos dos quilombolas. (Lauro)

Para o professor, não são devidamente respeitadas as características próprias da cultura quilombola, por exemplo, tanto o currículo quanto os tempos e espaços escolares deveriam respeitar as características próprias da comunidade remanescente quilombola, mas, na prática, não é isso que acontece. 
O professor Mauro destaca que é frequente na escola o número de brigas envolvendo as alunas desse espaço escolar.

Tem essa violência moral e algumas ameaças, mas é a violência física que é aqui... pelo menos na comunidade rural é mais evidente entre as mulheres. (Mauro)

A preocupação do professor encontra ressonância em outras pesquisas do gênero. Fante (2005) constata que é crescente a participação de meninas em condutas agressivas, comumente associadas aos meninos: "as meninas estão fazendo uso de maus-tratos físicos como forma de demostrar poder em seus grupos sociais" (p.66).

Outro tipo bem comum de violência que apareceu no relato dos professores foi o que se entende por bullying ${ }^{2}$, isto é, agressões verbais, apelidos preconceituosos e ameaças.

São xingamentos que eu presenciei da $8^{a}, 6^{a}$ série e $5^{\circ}$ ano; apelidos, palavrões, mexer com pai e mãe. (Maíra)

Agressões verbais, discussões e ameaças. (Pedro)

Segundos eles, as agressões verbais e palavras ofensivas são as formas mais vistas cotidianamente no interior da escola.

\section{A violência considerada a mais grave}

Há relatos que apontam a violência social e a não garantia dos direitos constitucionais como sendo a mais grave, uma vez que o desconhecimento da comunidade remanescente quilombola em relação aos seus direitos e garantias legais ainda é muito grande.

Elas discutem politicas dentro de uma visão de um grupo marginalizado e aí, em função disso, outros direitos acabam não sendo adquiridos (...) como se a miséria fosse agora um elo para se chegar às bolsas, para se chegar aos recursos. (Lauro)

\footnotetext{
${ }^{2}$ Bullying: é definido por Nancy Day (1996: 44-45) como abuso físico ou psicológico contra alguém que não é capaz de se defender. 
Assim, o relato acima demostra que o Estado não garante a infraestrutura mais adequada à escola, ignora a cultura quilombola, tornando-a marginalizada, e não garante a segurança da região.

Para os docentes abaixo, o tipo de violência mais grave na escola é a violência verbal e o bullying:

\section{É na verdade essas falas que eles dizem: "eu vou te matar", "eu vou te furar”, "eu vou te dar um tiro", elas soam com muita facilidade no nosso recreio. (Mauro)}

Eu acho que a mais é aquela que a pessoa leva pra casa, que fica na mente. Eu acho que aquela que a pessoa é que atinge mais o psicológico, né, da pessoa. (Pedro)

A violência verbal ou bullying consiste em agredir sem o uso da força física. Um agressor verbal pode ofender moralmente um agredido, criticando a sua cor, o seu corpo ou a forma de realizar determinadas tarefas.

\section{Como a violência é trabalhada em sala de aula}

Segundo verbaliza o docente, o tema da violência é trabalhado em sala de aula, porém não na profundidade desejada. Além disso, o professor se ressente da falta de segurança para trabalhar com um tema tão delicado.

A escola tem trabalhado. Algumas pessoas sentam, se discute muito; alguns professores trabalham, sim, mas não é de forma acentuada. Até porque o professor aqui, ele se sente refém, se nós... qual segurança que nós temos aqui para bater de frente com algumas formas de violência que acontecem aqui? Não temos proteção. Daqui até Abaetetuba nós estamos à mercê. (Lauro)

O professor faz referência à maneira como os professores retornam para Belém após um dia de trabalho. Isto é, fazem uma viagem de Rabeta ${ }^{3}$ que dura 60 minutos e não dispõe de muita segurança durante o trajeto.

Quanto à afetividade dos professores, o conjunto de respostas obtidas em entrevistas chama a atenção para o medo e para a insegurança que permeiam a relação

\footnotetext{
${ }^{3}$ Rabetas são pequenas embarcações motorizadas de pequeno porte. Essas embarcações funcionam como um meio de transporte nos rios, pois é apropriada para o transporte de pequenas cargas e passageiros, fazendo o percurso das comunidades das ilhas até cidade de Abaetetuba.
} 
entre professor-aluno, professor-comunidade. Tal emoção parece comprometer a própria forma de trabalhar a temática da violência em sala de aula.

Alguns professores verbalizam que a não só a violência, como também outros temas da atualidade são trabalhados por meio dos temas transversais. Contudo, eles acreditam que essas questões ainda são trabalhadas de forma isolada e individualmente por professores em sala de aula, seja pela falta de um projeto coletivo da escola, seja pelo tempo reduzido de cada disciplina.

De fato, a questão da violência está inserida nas nossas diretrizes, mas é trabalhada individualmente (...) não há uma reunião para nós fazermos uma palestra ou uma apresentação sobre esse tema. (Mauro)

Na verdade, não só a violência como também outros temas a gente procura introduzi-los no dia a dia, no estudo das disciplinas, só que, pelo nosso tempo ter sido reduzido, às vezes a gente deixa de lado algumas coisas. (Maira)

Batista e El Moor (1999) explicitam que o próprio fato de trabalhar a violência como tema complementar aos habituais conteúdos escolares exige um esforço redobrado, uma vez que, como os docentes sublinharam, não receberam e ainda não estão recebendo formação adequada para isso.

\section{Como os professores costumam agir diante da violência}

Para este professor, quando acontece uma situação violenta, tenta-se resolver a situação por meio do diálogo, e como a comunidade tem um traço religioso muito forte, tanto com a religião católica quanto com a religião evangélica, às vezes recorre-se a ajuda dos representantes religiosos locais para ajudar a minimizar o problema.

\footnotetext{
A maioria deles recorre à direção e chama os pais. À vezes chama-se o pastor da igreja, porque aqui é muito forte a questão dos laços religiosos. O pastor vem e conversa com o pai, com a mãe e com o aluno e tenta viabilizar uma solução. (Lauro)

É uma situação complicada em que as atitudes são diversas. Têm professores que olham e não fazem nada, porque não querem e por ficarem abismados. Outros que já tentam intervir, mas meio que com medo. Às vezes tem só mulher aqui dentro ou às vezes todo mundo sai, aí a gente se tranca por medo. (Maíra)
}

O relato acima sublinha o transitar entre a indignação e o medo de fazer algo. Fatos que são expressos quando a professora reflete que às vezes estão apenas as mulheres na escola e elas podem ser alvos de violência, haja vista que a estrutura física da escola não as salvaguarda devidamente. 
Em uma pesquisa realizada com professores sobre as representações sociais destes acerca da violência nas escolas, Placco (2005) encontrou algumas representações relacionadas às formas de enfrentamento utilizadas pelos docentes diante das manifestações de violência, a autora aponta três atitudes, quais sejam:

1) Atividade didática com o objetivo de usar o conteúdo da mídia para análise; 2) atividade didática realizada em equipe em que alunos cooperam uns com os outros; 3 ) não enfrentamento da violência (esquivando-se ou pensando) que não é papel deles, delegando para outros profissionais (p. 59).

Os três pontos apresentados acima são importantes para a presente pesquisa, considerando-se que abordam formas de enfrentamento da violência, pelos professores. Dessa maneira, constituem pontos de partida para o trabalho de formação de professores voltado para a violência.

\section{A formação sobre violência escolar}

Os professores relatam que não recebem nenhuma formação específica que os capacite a trabalhar com a violência na escola.

Estamos vendo acontecer, nós não paramos para analisar, para pesquisar que é o que vocês estão fazendo. Partindo do campo da nossa prática, as informações apropriadas iriam contribuir imensamente. (Mauro)

Um curso que oferecesse formas diversificadas de se trabalhar em sala de aula. (Maíra)

Olha, eu acredito assim que formas de como a gente pudesse abordar esse tema com os alunos, depois também como a gente pudesse chegar na família... a gente percebe que a família é muito isolada, mas também eu acho que a gente não dê muita abertura para eles. Eles também são muito ocupados, trabalham na olaria e no trabalho doméstico. (Clarissa)

Tal problema que assola a escola ainda não é conjuntamente discutido, não foram comtemplados na formação inicial e não há, por parte da Secretaria de Educação, um projeto que trabalhe com essa questão. Detectar o problema é o primeiro passo, entretanto, é necessário um esforço no sentido de preparar/informar/formar os professores para trabalhar com a violência na escola.

Placco (2002), ao abordar o papel da escola da prevenção à violência, sublinha a importância de que os programas de formação incluam objetivos relacionados à 
construção, pelos alunos, de uma hierarquia de valores que lhes possibilite a compreensão do valor da vida, do compromisso com a sociedade e com o grupo.

Pedro-Silva (2014) é um dos que advoga que o problema está na questão da formação docente. Para exemplificar, o autor verbaliza que muitos professores ainda não conhecem as teorias psicológicas sobre o desenvolvimento da criança e do adolescente. Além disso, há muitos docentes que ainda desconhecem teorias que subsidiam o processo de ensino-aprendizagem sobre a leitura-escrita. São essas lacunas na formação docente que fazem grande diferença na maneira de atuar do professor e, consequentemente, desembocam em um processo de indisciplina ou agressividade por parte dos alunos.

\section{A violência na relação professor-aluno}

O professor Mauro faz referência à violência simbólica expressa por meio de ameaças feitas por alunos:

Violência, olha violência nós sofremos quase todos os dias, violência psicológica se sofre quase todo dia. Todo dia tem um aluno que diz: 'Ah, professor se você não me der esse ponto vai acontecer isso com você'. (Mauro)

De acordo com Abramovay e Rua (2002), a primeira modalidade de violência contra a pessoa consiste em ameaças, isto é, promessas de causar danos ou de violar a integridade física ou psíquica de outrem. Assim como relatado pelo professor, as autoras confirmam que um dos principais motivos das ameaças contra professores são insatisfações ocasionadas por notas.

Os professores abaixo sublinham um aspecto da relação professor-aluno que às vezes é um causador de violência. A falta de diálogo, muitas vezes causado pelo stress do trabalho, pode fazer com que a relação professor-aluno seja permeada por atritos, que, se não resolvidos, podem ser desencadeadores de violência.

Olha, às vezes, sem querer, a gente trata o aluno de uma forma, não sei se é o estresse, talvez a carga horária altíssima, mas a gente poderia falar com eles de uma forma mais amena, com um diálogo melhor. (Clarissa)

Na relação professor-aluno, uma coisa que eu acho ruim e que já vi muito é professor ficar discutindo com aluno. (Kleber) 
Em se tratando das ameaças contra professores, os motivos mais recorrentes encontram-se nas desavenças ocasionadas por notas, pelo nível de exigência e por problemas disciplinares cometidos em sala de aula.

\section{A infraestrutura de escola $X$ violência}

De acordo com os professores entrevistados, apesar de a estrutura física não ser o fator determinante para a ocorrência de violências, haja vista que existem escolas muito bem estruturadas e que possuem índices elevadíssimos de violência, ela pode contribuir sim para engendrar a violência em suas diversas formas.

\footnotetext{
A nossa estrutura é precária. Inclusive, como a nossa área é totalmente livre e cheia de arvores, os alunos, eles fogem, se escodem com muita facilidade para fazerem o que quiserem escondidos. (Mauro)

Eu acredito que se a escola tem uma infraestrutura adequada para receber os alunos, se essa escola tem um suporte e infraestrutura... por exemplo, se tem uma sala de vídeo, e se você tem uma sala de computação, tudo isso, vai fazer com que o aluno se interesse. (Maíra)

Eu acho que a estrutura física da escola poderia ser melhor. Por exemplo, no momento não há internet aqui na escola. Tem a sala, tem os computadores, no momento em que eles estivessem com horário vago, eles poderiam estar lá pesquisando. Se tivesse uma biblioteca com mais livros também. Como não tem essa infraestrutura eles ficam aí fora. (Clarissa)
}

Kodato (2010) detaca que a falta de uma boa estrutura física ou pedagógica na escola propicia ambientes violentos, pois, segundo o autor, a falta de estrutura acaba criando um grupo de alunos excluídos do processo pedagógico, e esses alunos têm de mostrar que estão inseridos na vida escolar, ainda que de maneira violenta.

Reis e Conceição (2012), também destacam que esse "tédio" relatado pelos alunos durante as aulas pode estar na gênese de diversos tipos de violências, além de embasar a violência simbólica e, no extremo, excluir o "aluno problema".

Pedro-Silva (2014) acredita que há uma correlação entre as condições materiais das escolas com certos tipos de violência, pois o autor entende que salas pequenas, mal ventiladas, superlotadas e desconfortáveis aumentam a probabilidade de ocorrência de atos violentos.

\section{Consequências da violência para a escola}


Para os docentes, dentre as consequências da violência para a escolas, a mais nefasta é a evasão dos alunos:

Evasão de alunas gravidas, evasão de alguns alunos que não querem estudar, então a violência na verdade não começa na escola. (Mauro)

Na verdade, se a gente for ver a consequência da violência para a escola, seria a evasão dos alunos, porque, a partir do momento que o aluno pratica uma determinada violência dentro de um âmbito escolar, ele já é visto de um modo diferente. (Maíra)

Para ambos os docentes, os alunos que praticam violência na escola acabam sendo, de certa forma, marginalizados pelos outros alunos. Assim como a aluna adolescente que fica grávida também passa a ser "mal vista" por outros alunos da escola. Todos esses “olhares" acabam por intimidar e fazer com que o agressor ou a aluna grávida se retraiam e, no extremo, terminem por abandonar a escola.

Abramovay e Rua (2002) acreditam que, em casos como os acima relatados, o jovem fica estigmatizado como um "aluno problema", tornando-se conhecido negativamente por todos os profissionais da escola e pelos alunos.

Além disso, há relatos que associam a violência na escola às dificuldades de aprendizagem:

A gente percebe que o aluno, ele é agressivo, que é indisciplinado, em consequência disso ele tem um rendimento escolar menor. (Clarissa)

Torna-se mais difícil a aprendizagem dos alunos. (Kleber)

Batista e El Moor (1999) apontam que um dos efeitos mais cruéis da violência na escola é a desorganização do trabalho docente, oficio esse que depende não só da organização do ambiente de trabalho, como também da motivação e disposição do aluno para o aprendizado.

\section{CONSIDERAÇÕES FINAIS}

Quando se aborda o tema da violência nas escolas, há que se lidar com múltiplas contradições. Uma das maiores reside no fato de que, ao mesmo tempo em que a escola é um espaço de aprendizagem de conteúdos e de valores, bem como do exercício da ética e da razão, é também representada como um local de brigas, agressões físicas e verbais, 
ameaças e depredações. Lugar onde os conflitos se registram entre vários atores: alunos, professores, gestores, funcionários e comunidade.

Segundo os relatos, a violência está representada naquela escola sob a forma de violência sexual, violência doméstica, violência social (não garantia de direitos), violência racial (a característica quilombola da escola não é plenamente respeitada), ameaças, bullying, violência verbal, agressões e violência física. Entretanto, é recorrente na fala dos professores o entendimento de que é no ambiente familiar que o aluno toma contato com a violência e/ou que as famílias falham na educação de seus filhos ao não lhes proteger contra as "más influências". Essa falha da família seria um dos principais problemas, seguida pela estrutura social e econômica.

Em geral, por meio de normas, a escola lida com atos de agressividade e violência a partir de um elenco de procedimentos curriculares e extracurriculares. Os procedimentos adotados são: trabalhar o assunto durante as aulas, tentar criar um ambiente propício para se falar sobre a importância de valores educacionais e, principalmente, dialogar com os alunos, seja como forma de compreender as angústias discentes, seja como forma de estabelecer um diálogo aberto, objetivando a prevenção da violência. Porém, parece haver consenso, por parte dos professores, quanto a não efetividade dessas ações pedagógicas, uma vez que tais ações não têm surtido o efeito necessário. A maioria dos professores concorda que o Estado vem se omitindo de suas responsabilidades quanto à segurança da comunidade, dos alunos, da escola e de seus funcionários.

É interessante notar que a escola de característica quilombola é, contraditoriamente, como um lócus da violência racial, uma vez que há depoimentos evidenciando que aspectos importantes da cultura e das raízes remanescentes quilombolas não são respeitados no currículo, nos tempos e na organização da escola. Assim, as indicações sobre as percepções de exclusão social/racismo fazem da escola um espaço de exclusão social/discriminação.

A violência também possui desdobramentos que afetam negativamente a qualidade do ensino e a aprendizagem. Para os docentes, há consequências nefastas da violência para a escola, pois dificulta a concentração discente, faz com que estes percam a vontade de assistir às aulas, fiquem revoltados e, às vezes, inseguros, fatos que atrapalham o desenvolvimento acadêmico do alunado. 
Por fim, pesquisar as concepções de professores sobre violência nas escolas se mostrou especialmente importante para a compreensão do problema e para se orientar as reflexões e análises em busca de estratégias para a sua superação, porém são indispensáveis ações concretas, como a urgente necessidade de formação adequada para esses profissionais, bem como de políticas públicas para a primordial garantia de direitos das comunidades ribeirinhas e quilombolas, ainda desassistidas pelo poder público.

\section{REFERÊNCIAS}

ABRAMOVAY, Miriam; RUA, M. das G. Violências nas escolas. Brasília, Unesco, 2002.

BATISTA, A.S.; EL MOOR, P.D. Segurança nas escolas e burnout dos professores. In: CODO, W. (Coord.) Educação: Carinho e trabalho. CNTE, Brasília: UNB/Psicologia e Trabalho. Petrópolis: Vozes 1999. pp. 312 a 323.

CHARLOT, Bernard. A violência na escola: como os sociólogos franceses abordam essa questão. Revista Sociologias, n.8, jul./dez., Porto Alegre: UFRGS, 2002.

CHAUÍ, Marilena. Ética e violência. Teoria \& Debate, São Paulo, v. 11, n. 39, pp. 3241, out./nov./dez., 1998.

DAY, Nancy. Violence in schools-learning ir fear. Berkeley Heights, NJ: Enslow Publishers, 1996.

FANTE, C. Fenômeno bullying: como prevenir a violência nas escolas e educar para a paz. Campinas: Verus, 2005.

FRANCO, Maria Laura P. Análise de Conteúdo. São Paulo: Liber Livro, 2004.

HOUAISS, Antonio.; VILLAR, Mauro. Dicionário Houaiss da Língua Portuguesa. $2^{\text {a }}$ reimpressão. Rio de janeiro: Objetiva, 2007.

KODATO, Sergio. O Brasil fugiu da escola. São Paulo: Butterfly, 2010.

PEDRO-SILVA, N. Ética, Indisciplina \& Violência nas Escolas. Petrópolis, RJ: Vozes, 2014

PLACCO, V. M. N. S. Representações Sociais de jovens sobre violência e a urgência na formação de professores. Revista do Programa de Estudos Pós-graduados em Psicologia da Educação. São Paulo, v. 14/15, pp. 347-367, $1^{\circ}$ e $2^{\circ}$ sem. 2002.

PLACCO, V. M. N. S. As representações sociais de professores do ensino médio quanto à aids, às drogas, à violência e a prevenção. Relatório de pesquisa FAPESP, 2005. 
REIS, T. T.; CONCEIÇÃO, M. I. G. Violência nas escolas: tendências mundiais. In: AMPARO, D. M. (Org.) Adolescência e violência: intervenções e estudos clínicos, psicossociais e educacionais. Brasília: Editora UNB, 2012.

ZALUAR, Alba. Um debate disperso: violência e crime no Brasil da redemocratização. Perspectiva, São Paulo, vol. 13, n.3, pp. 3-17, 1999. 